\title{
The Techne of Making Your Ferry: A Non-Representational Approach to Passengers' Gathering Taskscapes
}

\section{Introduction}

Passengers are artful social agents who skilfully negotiate their passages' multifaceted spatial and temporal features. In related fashion, passages are performances: fluid, dynamic, ever-changing route-like "intersections of the material and social" (Lorimer and Lund, 2003, p. 134). In this sense journeys can be conceptualized as taskscapes (Ingold, 2000) and more broadly as techne (Heidegger, 1993). The focus of this article is on the taskscapes and techne of ferry passengers gathering for a sailing before its scheduled departure. These processes show how passengers are creative performers: culturally-situated, reflexive, embodied, mindful actors sharing a practical orientation to performing travail - that is, travel as work (Peters, 2006).

The mobilities literature is central to the present research. Recent scholarship has shown how mobility is generative of subjectivity, social organization, and place (Adey, 2009; Hannam, Sheller, and Urry, 2006; Sheller and Urry, 2006; Urry, 2000, 2008). Amongst other things, mobility is a mundane (Binnie, Edensor, Holloway, Millington, and Young, 2007), but meaningfully ritualistic (Edensor, 2003), artful (Watts, 2008), and highly heterogeneous and diffused bodily practice (Bissell, 2009) which occasions unique interaction settings and relationships (Laurier, Lorimer, Brown, Jones, Juhlin, Noble, Perry, Pica, Sormani, Strebel, Swan, Taylor, Watts, and Weilenmann, 2008). Aiming to contribute to a growing body of research on mobile cultures, this paper is driven by non-representational theoretical approaches (esp. Ingold, 2000) and by the methodological agenda of "mobile research" (cf. Buscher and Urry, 2009; Watts and Urry, 2008).

Whereas other researchers have mostly attempted to understand passengering by focusing only on the main leg of a journey my focus here is on the gathering phase of travel-where gathering refers to the activities preceding the principal component of a passage and leading to the "irretrievable event" (Dewsbury, 2000) of a scheduled departure. Rather than a mechanic fait accompli I posit gathering in performative terms in order to highlight "the tensions and correspondences that exist—at different scales, and for individuals or collective groups_between formalized configurations of coded acts and an improvised ream of creative acts" (Lorimer and Lun, 2003, p. 134) at stake in catching or missing a ferry's sailing. According to Schechner (2003) a performance is the whole of three parts: gathering, the playing out of an action, and dispersing. For example, in the performance of a bus journey the bus ride itself is preceded by activities such as setting out and waiting for the journey, and followed by moving on (e.g. see Jain 2009). In the context of islanders' travel to a mainland or larger island the main leg of their passage is the ferry ride across the 
water. But getting to a ferry terminal to embark (a form of gathering), and later disembarking and moving onward (a form of dispersing) are just as important components of their passage deserving scrutiny.

\section{Research Context and Method}

The setting for this research is the coast of British Columbia (BC), located in Western Canada. Stretching from the US border with Washington State to the marine border with Alaska the BC coast measures $965 \mathrm{~km}$ in a straight line. But due to the large number of islands, inlets, arms, and fjords the $\mathrm{BC}$ coastline measures about $27,000 \mathrm{~km}$. This is a rugged coast. Between Prince Rupert (pop. 18,000), located on the $54^{\text {th }}$ parallel North, and Metro Vancouver on the $49^{\text {th }}$ parallel North (pop. circa 2,000,000), there are no coastal roads and extremely few communities. The most populated of these is the Sunshine Coast area (pop. circa 50,000) — a district immediately north of metro Vancouver that is only reachable by ferry or small planes. To the west of the mainland lie several inhabited and uninhabited islands. The largest is Vancouver Island $\left(32,134 \mathrm{~km}^{2}\right)$, which is also the most inhabited $(740,876$ residents). Flanking the east coast of Vancouver Island are the Southern Gulf Islands and the Northern Gulf Islands: constellations of small islands, the greatest majority of which are either not inhabited or populated by less than 5,000 people. North of Vancouver Island, reaching up to Haida Gwaii (pop. 4,800), are hundreds of small, mostly unpopulated islands. Amongst the few populated ones are Denny Island (pop. circa 100), Swindle Island (pop. circa 300), and the most populated, Campbell Island (pop. circa 1,400). Access to these areas is provided by an extensive network of ferry boats owned and operated by the British Columbia Ferry Services Corporation, or BC Ferries. With the exception of the greater metropolitan Vancouver area, all the communities on the $\mathrm{BC}$ coast are dependent — in one way or another-on BC Ferries.

BC Ferries is a monopolistic, privately owned, but publicly subsidized and overseen company. It ranks as one of the world's largest ferry transportation companies with annual revenues in excess of CAD $\$ 640$ million and a fleet of some three dozen vessels of varying size. BC Ferries conducts operation in 47 ports of call through a multitude of routes ranging from 10-minute to 36-hours in length. Because there are no bridges competing with BC Ferries, these boats are seen as lifelines. People use the ferries for different reasons. For some the ferries are the door to the outside world, as

only a small grocery store and a post office may be available in their community. For others, ferries are the way to reach supermarkets, supply centres, specialty stores, health, education, administrative centres, workplaces, family members and friends, airports, or leisure destinations. Some people may travel as frequently as almost every day (as if often happens in the Gulf Islands) or as infrequently as once, twice or half a dozen times a year (as it often happens on Vancouver Island, the North and Central Coast, and the Sunshine Coast). 
Regardless of an individual's frequency of travel, ferry boat mobility plays a key role in the social organization and culture of these communities. Not only are the ferries key players in economic development, but they are also cornerstones of a community's way of life. On any given day, it is not unusual to hop on a morning ferry and run into friends, acquaintances, relatives, and neighbours headed "to town," only to find them again coming back home on a later sailing. Even when one is not travelling, ferries shape life. When a ferry is 20 minute late, it seems as if a whole community is 20 minutes late. When a ferry is busy, a whole community's pace feels rushed. Ferry fares have a key impact on community's economic sustainability. And perhaps most significantly—and yet most subtly-ferries transform communities by setting them apart their mainland counterparts.

Data for this article are drawn from a larger ethnographic study. Fieldwork data collection formally began in the spring of 2006 and ended in the summer of 2009, however my personal experiences as an islander and ferry user can be traced back to 2001. Data collection unfolded as a threefold strategy. The first component entailed extensive travel by ferry boat, which allowed for participant observation. I reached each of the communities served by BC Ferries via regularly scheduled ferry service multiple times, for a total of over 250 trips. The second component of the fieldwork is comprised of about 400 qualitative, semi-structured interviews with a diverse sample of island and coastal residents. The third component of the research design included an inventory of publicly available information on BC Ferries. Such information was collected through local and regional newspapers, local library archive collections, internet forums, and private archives.

\section{Findings and Analysis: How to Make a Ferry}

Much of mobility is a mundane accomplishment. Everyday life is teeming with "forms of mobility that are enduring, predictable, habitual, repetitive, and of brief duration and short distance" (Binnie et al., 2007, p. 166). Yet, despite their seemingly unremarkable aspects, everyday mobility and travel are an art (Adler, 1989; Peters, 2006; Watts, 2008).

Passengers are like artists as they seek to accomplish their purposes and interact with instrumental tools in reflexive and creative ways. As travellers perform their journeys they interact with space and time, "crafting" (Watts, 2008) meaningful social and geographic relations. To be sure, not all passengers are informed, capable, perfectly strategic, rational, inspired actors. However viewing interaction with transport technologies as an emergent and agentic unfolding of skilfulness highlights how passengering can be creative and artful. Wrongfully, art and technology are often treated as separate. But such oppositions miss an important point: behind both artistic and technological performance lie skilful acts of poiesis, in other words, techne. Drawing from Heidegger (1993) Ingold (2000) explains how the concept of techne encompasses both the skilfulness and the artfulness of intelligent action. "Originally," writes Ingold (2000, p. 349 original emphasis), 
"tekhne and ars meant much the same thing, namely skill of the kind associated with craftsmanship." Surpassing the contemporary separation of art and technology ought to yield great insights into the creativity of all human practices, passengering included.

Treating ferry-catching as techne is intended to highlight ferry passengers' practical and creative engagement of their surroundings, and in particular their use of tactics necessary for effective gathering, their dwelling skills and local knowledge in managing the "complex topographies of apprehension" (Edensor, 2003, p. 152) involved in making a sailing. The techne of making a ferry indeed is about artful, skilful making; whereby making refers to successful performance of one's task, of catching a ferry before it sails off without you. Building upon Ingold (2000) we can treat the techne of ferry-catching as a threefold manifestation of skill. Firstly, passengers interact with temporal and spatial elements in the process of catching a ferry, negotiating material features of their environment, engaging with the situational circumstances of their action, and responding to multiple demands emerging in the field as a result of movement patterns. These can be referred to as orientation skills. Secondly, gathering for a sailing involves not the repetitive implementation of a preconceived design, but "calls for care, judgement, and dexterity" (Ingold, 2000, p. 347) in revising lines of action as journeys to the ferry terminals unfold. These are skills of reflexive movement. Thirdly, passages have a story-like quality because like evolving story lines passages change over time, and even within the same passage, passengers need to grow rhythmically with evolving circumstances. The performance of passengering therefore demands adaptive skills.

Orientation, adaptive, and reflexive movement skills are critical to transport users because making a ferry matters, and it matters greatly. To be sure, catching "a" ferry, any ferry, is not as important as making "that" ferry, "your" ferry. Islanders and coasters plan travel as a series of tightly connected moves which put them in a position to need to catch specific sailings. For example, to reach the Vancouver International Airport by noon a Gabriola islander needs to catch the 7:45am ferry to the mainland from the Duke Point ferry terminal on Vancouver Island. That means leaving Gabriola Island with the 6:45am ferry, arriving on Vancouver Island at 7:05am, and getting to the Duke Point ferry terminal at around 7:25am. Catching that 2-hour sailing from Duke Point means disembarking on the mainland at 9:45am and arriving at YVR at 10:10am. If one misses the 6:45am ferry, or if that ferry is late and it causes one to miss the 7:45 connection, missing one's flight is inevitable. "Performativity is about connection" to other events, roles, relationships, and actors (Dewsbury 2000:476): a scheduled departure is a happening whose affective immediacy catapults passengers into the realm of risk and chance, of suspense and drama (Dewsbury, 2000). Complex travel connections obviously dramatize the significance of catching “your ferry,” but even simpler journeys-cum-assemblages 
such as a morning commute to work or school are meaningful "connections" enabled by successful ferry-catching. As Robert, a Quadra Islander, explains:

If you don't catch your ferry all hell breaks loose. I mean, sure, there are times and days when a missed sailing is a beautiful opportunity to kick back, open a cold drink, and maybe light up a smoke. If you are departing-as opposed to returning-you might even be able to go back home, make yourself a sandwich, and try your luck later with the next sailing. But most days, life is not like that. You've got somewhere you gotta go. Missing a ferry is like bumping against one of those pyramid-shaped promotional displays of pop cans piled up on top of one another at the grocery store. You hit one can and the whole pile falls down.

Missing “your ferry” may mean that doctors' appointments are to be cancelled, flights are missed, employers are angered, exams are failed, romantic dates are upset, and much more. Besides having to deal with the practical implications of a missed sailing, failing to catch a ferry is also a case of poor performance display. There is indeed a certain element of playful competition at stake in the performance of gathering, not unlike in the practice of hill walking (Lorimer and Lund, 2003):

Here on the island when you miss a ferry most of the times you put on a show. You get to Lyall Harbour when there are still a lot of people mingling around because they got off the ferry or they dropped something or somebody off. You're not alone. These are all people you know, at least on a small island like Saturna, and they know you. Missing that ferry is a failure right under their eyes. I mean, nobody laughs at you because tomorrow it could be them, but for us islanders catching ferries is not a hobby. For an islander to miss a ferry is like for a professional soccer player to miss a penalty kick.

\section{Taskscape Components}

A successful performance demands that a passenger be able to negotiate multiple taskscape components, such as, firstly, the linearity of clock time. Making a passage requires passengers to "craft travel time" (Watts, 2008, p. 720), but their work begins early, well before the main leg of a journey. This is no easy task. Not everything runs on clock time on small BC islands and the $\mathrm{BC}$ coast. The ferries, however, do. Their timetables work as intrusions into the relatively relaxed and slow-paced lifestyles of peaceful communities. There, many people dwell on a by-product of clock time known as "island time" (or "coast time" on the Sunshine Coast). Island time is the product of linear time (e.g. the present season, day of the week, time of the day), subjective dispositions (e.g. one's mood, energy, employment status, age) and place of residence. For instance, Chris is a self-employed artist living on Hornby Island. She is 37, and she moved here 12 years 
ago from Vancouver, fed up with the city's hectic life pace. Whenever she has to go to Vancouver her mood is "rotten." She says:

I can't stand that trip. It's a shock to the senses. Not only do I have to catch three ferries just to get there, but having to get up two or three hours earlier than normal means that I actually have to set up an alarm call. And I don't even have an alarm clock! I mean, I don't even own a wristwatch. I moved here because I didn't want to have to carry a wristwatch anymore. So I have to ask a friend to give me a phone call so I can get up in time. But do you think it's easy to find a friend that gets up at 7am? So I end up trying to figure out how to make all these adjustments from island time to clock time just to catch a ferry.

Island time is also the by-product of ferry timetables. In places where few people carry wristwatches or cell phones, islands serve as common clocks. "If you want to catch a ferry never mind looking at a watch," tells me Terri from Cormorant Island, "just put yourself in a position where can tell the ferry is coming, and then make a move when it's close enough. For me, my living room window looks out to the harbor. You see that tall cedar tree, left of that yellow house? When I sit here on this chair and see the ferry reach that cedar I know it's time to get out of the house and go down to catch it." Visual recognitions of movement as ways of telling time take other forms too. For example, on Denman Island catching a ferry is often a race against Hornby Island ferry passengers. Hornby islanders need to take a ferry to Denman first, before catching the ferry to Vancouver Island. For Denman islanders beating the Hornby traffic therefore may mean making it, or not making it, to Vancouver Island before their ferry loads up. Thus, is not uncommon for them to phone friends who live on the eastern side of the island-with visual access to where the Hornby ferry docks_- to find out whether their pesky neighbours have disembarked, and thus whether it is time to go.

When we think of the process of gathering for a ferry sailing as a taskscape we become sensitized to the mutual interlocking of passengers' performances of movement. Like orchestral music the performance of a gathering unfolds as an interaction of diverse journeys, each with their pace and rhythms, each with their purpose and style, each with their means and trajectory. These passages, borrowing from Edensor (2003, p. 156) are "full of moments of brief copresence as vehicles convey different bodies at different speeds, constituting myriad excursions of varying duration, distances, purposes, and destinations. Tourists, commuters, commercial travellers, visitors to family and friends: the innumerable permutations." A passage, again building upon Ingold (2000, p. 198) can therefore be understood as "the taskscape in its embodied form; a pattern of activities 'collapsed' into an array of features" (2000, p. 198) and emerging "as nodes in a matrix of movement" (2000, p. 219). 
Timetables play an especially important role in gathering processes (Hodson and Vannini, 2007; Jain, 2009).

Every community has its own ferry timetable: some islands have one sailing a week, others have five, or eight, or maybe seventeen daily sailings. This may mean needing to memorize much information in order to act intelligently, and quickly. If memorization of multiple schedules is impossible because of schedule complexity, as Sarah, a Saltspring islander explains, other options exist:

We have three ferry routes here, three different terminals. But most of us only catch one regularly. For example, if you work in Victoria you'll know the Fulford schedule like the back of your hands. But if you need to go to Duncan or Nanaimo for shopping then you start thinking of who you know that catches the ferry out of Vesuvius. Say, Bill does. So you phone Bill to ask him which one is the best ferry to catch, if it's crowded, how early you should get there, who's on that ferry, and all that. You might even find out that he's going on the later sailing, so you decide to carpool. Or if you're lucky he might just offer to pick up whatever you need from town.

Like maps, timetables can be complex to read and demand important orientation skills (also see Lorimer and Lund, 2003). On Denman Island for example there are seventeen daily sailings to Vancouver Island. The schedule includes symbols such as \#@\$++!!—which, despite appearances, do not denote anger or frustration. The symbol “\#” denotes that the 9:40am sailing is busy and has the potential to overload. The symbol “@” corresponds to "daily except Sundays." The symbol “!!” indicates that the 6:00pm sailing from Buckley Bay is the last ferry connecting to Hornby Island, with the exception of Fridays, as the symbol "++" indicates for the 10:00pm sailing. And the symbol "\$” indicates that you actually have to pay for all of this. Though, in all honesty, you only have to pay at Buckley Bay. The return trip from Denman West is free, but you have to figure this out on your own.

The next taskscape element is traffic. Traffic information is critical in locations—-the majority-where sailing reservations cannot be made. And even where reservations can be made, it is not uncommon to find passengers who feel antipathy towards them, in part because they cost extra, and in part because just like many hill-walkers reject GPS technology, "a particular ethic of traditionalism in respect to skilled navigational practice" prevails amongst them (Lorimer and Lund, 2003, p. 141). Indeed, "reservations"—a Vancouver Islander once told me—"take away the fun from the whole thing." To calculate the odds of making that ferry you must take into account key temporal markers. Summer sailings are always busy, but selected winter dates like Canadian Thanksgiving (which is different from American Thanksgiving) and the Christmas season (which may feature a special holiday schedule, but only for some routes) are busier. Weekends are often busy, but not uniformly so. Saturdays are generally slow, whereas Friday 
afternoon and evening sailings, and Sunday morning and afternoon sailings are very busy. But many weddings take place on Saturdays in the Gulf Islands, so some Saturdays may be busier than all other days. During the workweek commuters tend to crowd sailings departing around 7am and returning at around 5pm, but school children can make other sailings very crowded, especially those around $8 \mathrm{am}$, and returning at around $4 \mathrm{pm}$. To help with all this on islands served by small loading-capacity ferries like Cortes Island the local newspaper carries important dates and announcements of unusually heavy traffic. Notices on any event, ranging from little Timmy's birthday party — to which a large family coming to the island from Campbell River has been invited — to a corporate retreat crowding the only resort on the island are featured. Reflexive movement and adaptive skills, in short, are quintessentially important to master traffic.

Next, one needs to be aware of cutoff policies. One of the conveniences of ferry travel is that you can get to the ferry at the last minute. Well, sort of. Depending on the size of the terminal, the traffic it accommodates, how you get there (e.g. driving vs. walking), and other inscrutable conventions, different sailing cut-offs are enforced. Some are two hours, some are ten minutes, some are five, and some are three minutes. And some do not exist. Now, these are only formal rules, and their application is very idiosyncratic. If it's late at night and it's the last sailing, the cut-off won't probably be enforced. If you know personally the ticket booth attendant, the cut-off won't matter either. But if the ship's captain has it in for you the cut-off will be enforced for you and everyone else around you in the line-up.

Thanks to their orientation skills, many islanders are masterful at the art of catching a ferry at the last minute, or right before the cut-off. They always seem to appear at the terminal right before the bar comes down or the light turns to red. Others are prudent by nature, and daring enough to fight off the ridicule that being the first in the line-up brings. And others even engage in playfully adaptive but mildly subversive tactics (cf. de Certeau, 1984). A Powell River resident shared with me this story:

A friend of mine and I were driving our trucks onto the ferry at Comox. I was ahead of him by fifteen minutes. He knew he wouldn't make the ferry. So, he got on the radio and called me, "hey, I'm coming up the hill, I'll be there soon, but not soon enough, can you hold the ferry for me?" "Sure!" I said. A few seconds later the crew started loading us. As soon as it was my turn I drove onto the ramp and then into the ferry. But right as half my axels were onboard and half were still on the ramp I turned off the engine. I made it look like I was having engine trouble, you know. I got off the cabin, asked for help, got some crew involved, and this and that. Then, after 10 or 15 minutes of this I got back into the truck cabin and heard that my friend had now arrived at the terminal. At that point I turned the engine back on and made it look like the engine was working well now. And we all finished loading the ferry within minutes, my buddy included. 
This brief story shows us how "passages are relational" (Peters, 2006, p. 179); no two trips to the ferry terminal are exactly alike. Indeed mobility's “mundaneity is always potentially otherwise” (Binnie et al., 2007, p. 167): changing circumstances, diverse gathering styles, and differing configurations of action and purpose give rise to different gathering performances. These performances can be thought of as adaptive tactics (cf. de Certeau, 1984, p. 37) that are "generated through the process of movement-making itself' (Bissell, 2009, p. 186). These tactics are strategic and planned, but because of the emergent character of gathering, they can only be successfully planned in part. "We know as we go," writes Ingold (2000, p. 239), "not before we go," and therefore gathering tactics are more similar to "arts of making do" (Crang, 2000, p. 150) than they are to efficient blueprints awaiting mechanic execution.

All vessels in the BC Ferries fleet allow for vehicle loading, so in the majority of cases a passenger's journey is a combination of driving to the ferry terminal, loading the car onboard, and driving off to a different location. Negotiating the interpersonal rules of driving to the ferry terminal is a culturally rich process in itself. Indeed ferry-catching is a gathering performance "involving skilful interaction between [passengers] in accordance with the regulations and cultural norms of the road" leading to the terminal (Edensor, 2003, p. 155). For instance, on small islands like Cortes there is only one road that loops around the island, leading back to the ferry terminal. As Ross explains:

Small island roads are driven by two kinds of people: those who have to catch a ferry, and everybody else. On Cortes there are only six times a day when people drive because they have to catch a ferry. When you're driving around those times you don't pass anybody. Overtaking a vehicle is a like a declaration of war. Chances are that the vehicle you're passing is going to the ferry terminal too, so you're decreasing their chances on making it onto the ferry. I mean, there are 800 people here, and we all know each other. How are you going to feel when you get to the line-up before your neighbour, and a minute later your neighbour arrives and parks right behind you?

Driving know-how, and thus orientation skills, comes into play in other forms too. On Denman Island there are two roads to get to the Hornby Island ferry terminal: a main road and a "back road." The main road tends to be frequented by tourists, who follow the signs upon exiting the ferry from Vancouver Island. The back road, instead, is a "locals only" affair. Not only is the back road straighter, thus allowing for greater speeds, but it is also less trafficked. Because the Hornby ferry is smaller than the Denman ferry, taking the back road can mean catching your ferry or missing it. On Quadra Island instead—an island that Cortes Island ferry passengers cross to get to their ferry terminal— a different problem of adaptation exists. During winter sailings the ocean can be quite rough. Rough waters are not good for the vehicles loaded upfront on the open car deck; salt water spray is highly corrosive of car bodies, and it is therefore 
best to be loaded further back. In order to guarantee that position on the car deck Cortes Islanders engage in what they call “the Quadra shuffle.” Upon unloading the Quadra Island ferry en route to Cortes they lollygag around the island in order to let other drivers-less strategic, or perhaps less worried about their cars— to get ahead of them in the Cortes line-up and thus on the car deck.

Two more actors play an important role. Catching a ferry is always affected by the weather. The sun brings people out of their homes and occasions heavier than normal tourist traffic. The snow-which is rather uncommon on the West Coast of Canada_makes steep hills, narrow-winding roads, and mountain passes very treacherous. Fog is awful for navigation and it messes with schedules. And even tides need to be factored in, Mike and Julie, a farming couple from Malcolm Island explain:

We have a horse trailer and when the tide is low the ramp leading onto the car deck of the ferry gets very steep, so steep, especially during dramatically low tides, that the loading crew will stop you from trying to drive your trailer onboard. Now, we take our horses to shows and other events which are sometimes on the mainland. So, we can't just wait for a high tide or we might miss our show. This means that we have to always plan our travel not only with the ferry schedule, but also the tide tables.

Furthermore, high winds cause high swells and result in cancellations. Passengers in the North coast—where sea passages are less protected—know that their trips are always weather-dependent and demand constant adaptation. As Sally explains:

Getting to the ferry terminal is not the hardest part about catching our ferry; leaving the actual dock is the hardest part. The captain won't leave the dock if the swells are too big. This means that you could be sitting on the boat in port for 12 hours, one day, or more. Once I waited three days waiting for the winds to die down. When this happens the people that live in Queen Charlotte City or Skidegate, near the terminal, just drive back home and wait for the ferry in their homes, phoning in every now and then to check. My girlfriend has missed at least two or three ferries that way because she went home and fell asleep or forgot to check in.

The capriciousness of the weather shows us how ferry boat sailings afford passengers the possibility of a safe passage across water at a desired time, but the potential of these affordances remains to be actualized by the actual performance of passengers' gathering. As such, as passengers begin to plan their journey, scheduled sailings work for them as a "deferred affordance" (Bissell, 2009, p. 178) opening up an “ensemble of possibilities” (de Certeau, 2002, p. 98) to be actualized through successful movement. The process of gathering for a ferry in order to catch it is a bit like a drama unfolding over time in successive but unpredictable ways through which would-be ferry passengers continuously adjust their 
journeys. In this performance passengers' skills are “crystallisation of activity within a relational field, its regularities of form embodying the regularities of movement that give rise to it” (Ingold, 2000, p. 345).

Catching your ferry means getting to know your ferry and adapting as it changes. Vessels occasionally undergo replacement and during these periods temporary, smaller replacement vessels are dispatched. Stephanie works in North Vancouver and commutes to Bowen Island. She leaves work at 5pm, gets to Horseshoe Bay at 5:20 and catches the 5:30 ferry home...

...but when the Queen of Capilano goes down we get the Bowen Queen, which is smaller. The Bowen Queen loads up by 5:10, 5:15. Meaning, anybody who arrives after that time would normally make it onboard the Queen of Capilano, but is two or three or four cars behind the last car in the line-up to make it aboard the Bowen Queen Sometimes it's okay to ask my boss to leave a few minutes early, but other times you have appointments leading up to 5 o'clock. So, if I want to catch my ferry home I need to take into account replacement vessels weeks in advance and plan my appointment schedule accordingly!

In sum, successful gathering performances only come about, become actual, "through events, though being performed," and performed right (Dewsbury, 2000, p. 481). The taskscape of gathering is an emergent field, saturated with possibilities of what may happen next, what could and would have been otherwise, whatever came out of convergences, connections, disconnections, and mis(sed)connections.

\section{Conclusion}

As the data have shown, making a ferry is an outcome of the practice of orientation, reflexive movement, and adaptive skills. Capricious weather, dramatic tides, pesky alarm clocks, strange road rules, unpredictable staff and crew, complex norms, changing vessels and mutating sailing conditions are all material, spatial, and temporal actors playing important roles in the performances of islanders' everyday mobilities. These performances necessarily require artful, crafty, skilful ways of mastering these mobilities for the sake of sheer survival on ferry-dependent islands. Though these skills have been examined here in the highly idiosyncratic context of catching ferries in British Columbia, all students of transport ought to keep in mind their importance regardless of transport mode and location. These skills are particularly important especially within the context of habitual travel planning and in the phases of familiar travel that precede the act of boarding public transport. These phases_- the "gathering" phases of spatial mobilities_-tend to be those that are the least structured by formal arrangements and official organizations' rules and plans, and thus the most likely to be subject to the sharing of lay and insider-only knowledge, the trials and tribulations of informal learning, and the slow initiations 
to place-based subjectivity and community membership. How occasional travellers gather and what skills their mobility performances require remains largely to be discovered by future research, however.

Furthermore, as the data have shown gathering for a sailing is an artful practice: a form of techne. Making a ferry is like weaving a journey together. The weaving metaphor (Ingold 2000, p. 346) epitomizes the practical, performative engagement of the ferry-catching passenger. Weaving is a form of orchestrated, emergent movement and so is catching a ferry. Like weavers, ferry passengers do not begin their journeys to the ferry terminal with an exact idea of the passage they wish to make and how that passage will unfold. Passages are thus not the forms generated by passengers' mental activities and exhaustive rational planning, but rather the outcome of adaptive practice of travellers and their emergent problem-solving (Peters, 2006). Passages begin "in the always social, material, and imaginary work of creating the destination" (Watts 2008:714) and evolve constantly, changing shape as passengers practice their kinaesthetic, orientational, and adaptive skills. Hence, like any product of weaving, a passage "comes into being through the gradual unfolding of that field of forces set up through the active and sensuous engagement of practitioner and material" (Ingold, 2000, p. 342).

In conclusion, practices such as making a ferry demonstrate how passengers are active social agents who, through their mobile spatialities and temporalities, manage to skilfully weave together the dimensions of their everyday mobilities. Through ethnographic evidence this paper has shown that despite their seemingly unfashionable traits, banal acts of mobility such as catching a ferry are rich with social significance. As Binnie and colleagues (Binnie et al., 2007, p. 166) have elegantly suggested "the car, the bus, tube, tram, train, and bicycle journey to work or the shops are far more central to the human experience of mobility than the jet plan excursion across the world." Journeys by ferry boat-an entirely neglected topic in the mobilities literature-are similarly central in the lives of many of the world's island and coastal dwellers. As research on the experiences of passengers and the social and cultural aspects of the spatialities and temporal rhythms of their practices continues to grow, social scientists can shed further light on the practical competencies and the delicate_-but artfully complex_intersubjective accomplishments of passengering.

\section{Acknowledgement}

This research was made possible through funding by Canada's Social Sciences and Humanities Research Council (SSHRC). I wish to acknowledge the research assistance of April Vannini and the editorial guidance of the editors and reviewers of this special issue.

\section{References}

Adey, P., 2009. Mobility. London: Routledge. 
Adler J., 1989. Travel as performed art. The American Journal of Sociology 94(6), 1366-1391.

Bissell, D., 2009. Conceptualising differently-mobile passengers: geographies of everyday encumbrance in the railway station. Social \& Cultural Geography 10(2), 173-195.

Binnie, J., Edensor, T., Holloway, J., Millington, S., and Young, C., 2007. Mundane mobilities, banal travels. Social \& Cultural Geography 8(2): 165-174.

Buscher, M., Urry, J., 2009. Mobile methods and the empirical. European Journal of Social Theory 12(1), 99-116.

de Certeau, M. 1984. The practice of everyday life. Berkeley: University of California Press.

Crang, M., 2000. Relics, places and unwritten geographies in the work of Michel de Certeau (1925-86). In: Crang, M., Thrift, N., (Eds), Thinking Space. London: Routledge, pp. 136-153.

Dewsbury, J.D., 2000. Performativity and the event: enacting a philosophy of difference. Environment and Planning D: Society and Space 18, 473-496.

Hannam, K., Sheller, M., and Urry, J., 2006. Editorial: mobilities, immobilities, and moorings. Mobilities 1(1), 1-22.

Heidegger, M. 1993. Being and time. New York: Harper.

Hodson, J., Vannini, P., 2007. Island time: the media logic and ritual of ferry commuting on Gabriola Island, B.C. Canadian Journal of Communication 32, 261-275.

Edensor, T., 2003. M-6 Junction 19-16: defamiliarizing the mundane roadscape. Space \& Culture 6(2), 151-168.

Ingold, T., 2000. The perception of the environment. London: Routledge.

Jain, J., 2009. The making of mundane bus journeys. In: Vannini, P., (Ed.), The cultures of alternative mobilities: routes less travelled. Surrey: Ashgate, pp. 91-109.

Laurier, E., Lorimer, H., Brown, B., Jones, O., Juhlin, O., Noble, A., Perry, M., Pica, D., Sormani, P., Strebel, I., Swan, L., Taylor, A., Watts, L., and Weilenmann, A., 2008. Driving and 'passengering:' notes on the ordinary organization of car travel. Mobilities 3(1), 1-23.

Lorimer, H., Lund, K. 2003. Performing facts: Finding a way over Scotland's mountains. In: Szerszynski, B., Heim, W., Waterton, C., (Eds), Nature performed: environment, culture, performance. London: Blackwell, pp. 130-144.

Peters, P., 2006. Time, Innovation, and mobilities. London: Routledge.

Schechner, R., 2003. Performance theory. New York: Routledge.

Sheller, M., and Urry, J., 2006. The new mobilities paradigm. Environment and Planning A 38, 207-226.

Urry, J., 2000. Sociology beyond societies. London: Routledge.

Urry, J. 2008. Mobilities. New York: Polity. 
Watts, L., 2008. The art and craft of train travel. Social \& Cultural Geography 9(6), 711-726.

Watts, L., Urry, J., 2008. Moving methods, travelling times. Environment and Planning D: Society and Space 26, 860-874. 